\title{
Low-cost surveys of the Domus of Stallius Eros in Pompeii
}

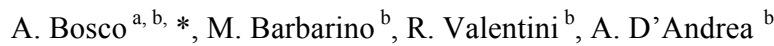 \\ ${ }^{a} \mathrm{PhD}$ student, University of Salerno, Department of Cultural Heritage, Salerno - Italy \\ ${ }^{\mathrm{b}}$ Centro Interdipartimentale di Servizi di Archeologia, Università degli studi di Napoli L'Orientale, Napoli - Italy. \\ *Corrisponding autor e-mail: a.bosco14@studenti.unisa.it
}

Commission V, WG V/4

KEY WORDS: 3D Model, Photogrammetry, 3D-ICONS, Total Station, Pompeii

\begin{abstract}
:
In the framework of the Project 3D-ICONS (www.3dicons-project.eu), different large archaeological models were acquired in Pompeii. In particular, the 3D Model of the House of Stallius Eros (Regio I, Insula VI, 13 - 14) was realized. This house conserves a rich vertical stratigraphy covering a large chronological period and offers interesting information about the development of this side of the ancient city. To implement a detailed survey of the house and to reconstruct the original structure of the domus, different types of survey were carried out, in order to provide a complete 3D model of the house. Three data-acquisition methodologies were used and their final results were compared in order to measure their accuracy, efficacy and velocity. At first, the domus was surveyed by an electronical total station, then two different interventions with un-calibrated photogrammetry were planned. The paper presents some preliminary results obtained by the three methodologies and the integration of the three models. The computational environments reproducing the ancient Domus of Stallius Eros allows to propose new archaeological interpretations and hypothesis about the reconstruction of the ancient House.
\end{abstract}

\section{INTRODUCTION}

In the framework of the Project 3D-ICONS, addressed to digitize a series of architectural and archaeological masterpieces with particular reference to European culture, different large archaeological models were acquired in Pompeii by the CISA, (Centro Interdipartimentale Servizi di Archeologia), of the University of Naples "L'Orientale". In particular the work focused on less known archaeological areas, but likewise relevant for the analysis of the different masonries and stratigraphical superimpositions. Among these areas particular attention has been dedicated to the House of Stallius Eros (Regio I, Insula VI, 13 - 14), which conserves a rich vertical stratigraphy covering a large chronological period and offers interesting information about the development of this side of the ancient city (see Figure 1).

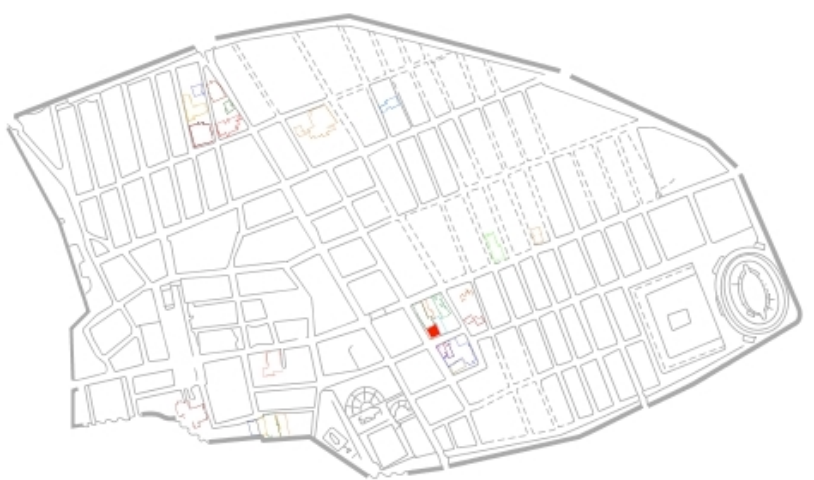

Figure 1. General plan of Pompeii. The red square highlights the location of the Domus of Stallius Eros.

It is evident that a complex site such as that of Pompeii, consisting of several structures of different types and with different levels of details, requires more techniques and methods for 3D modelling.
Even if the total station is an instrument quite frequent in the contemporary archaeological excavations, some limitations reduce the use. In particular the main limit is represented by the amount of time need for the acquisition of the data due to the quite manual process of data-capture. Both massive use of reference targets and, as alternative, manual application of a reflecting prism in each recorded location are time consuming operations. On the other hand, the precision with which this survey operations are carried out are strongly operator dependant and affect the high level of precision of the instrument. Finally, the survey obtained with the total station has no information about colours and materials of the surveyed structures.

For these reasons, during last decades several new techniques were introduced in the archaeological field in order to compensate these deficiencies (Eisenbeiss et al.,2005).

A promising technique is the un-calibrated photogrammetric survey. This is increasingly present among the techniques used to facilitate archaeological mapping and research, but still clashes with the prejudices of some researchers regarding the accuracy of the survey. As regards the aerial photogrammetry, however, the difficulties are increased because of costs and management of drones equipped "ad hoc", but the growing demand for UAVs in various sectors (from the agrarian to surveillance in football stadiums), produced in the recent years cost reduction and improvement in the quality of the vehicles.

The following sections show a short historical and archaeological description to highlight the issues of the site and the reasons for the choice of the techniques applied to the case study. Then, the surveying techniques are shortly summarized and some of acquired and processed data are shown. Finally, the results obtained by means of each method are compared, to give some preliminary conclusions and to indicate future developments. 


\section{HISTORICAL AND ARCHAEOLOGICAL CONTEXT}

The domus was excavated between 1926 and 1927, by the archaeologist Amedeo Maiuri (Maiuri, 1929), but no precise stratigraphic data have been registered and surveyed. It had two levels currently witnessed by two stairs. It was relatively small for roman standards, with about $300 \mathrm{~m}^{2}$ for the first floor. The rooms open onto the west side of the tuscanic atrium, while the access to a small garden was on the north side. Such zone (tablinum) had a floor in cocciopesto decorated with white tiles forming a pattern in meanders and rhombus. A complex hydraulic system was set up before the house was destroyed. Restructuring operations were certainly performed few years before the eruption of $79 \mathrm{AD}$. Some coins found during the excavation suggest a date about $65 \mathrm{AD}$.

According to Maiuri hypothesis, the house was a complete ruin before the final eruption of Vesuvius. He concluded that the large pile of sand in the rooms around the front hall rendered this house uninhabitable and indicated that it had been adapted as a private storage area for building material. Figure 2 clearly shows below the pumice stone due to the eruption a dark deposit representing the state of abandonment of the house already before the eruption.

In the framework of the project "Pompeian Households: An Online Companion", Allison included this house in a group of 30 houses so-called atrium houses. All, except one, have at least one garden as well as the defining front hall, or atrium (Allison P.M., 2004).

After the excavation of the twenties, no other in-depth analysis has been done in this area. In the last months, the study of the life the house has been taken in the framework of a MSc Thesis at the University of Naples L'Orientale.

On the other hand, it is worth to note that a strong attention is paid to correctly use survey techniques for the site of Pompeii. This attention was magnified by recent several damages. Indeed, the interventions including the use of $3 \mathrm{D}$ models are contained in the preservation program for the "Grande Progetto Pompei" activities.

The first aspect to be investigated for preserving these kind of historical monuments is the right interpretation of the building phases. For example in this case, simple observation of the walls of the house show that several heterogeneous structural interventions over time. Many architectural techniques are recognizable, some of the oldest known to the city (by frame and block) alternating with newer techniques.

All these information could be included in a comprehensive 3D model, which can replace the traditional record by unifying the geometrical information (from survey) with the structural information (from photos and investigations).

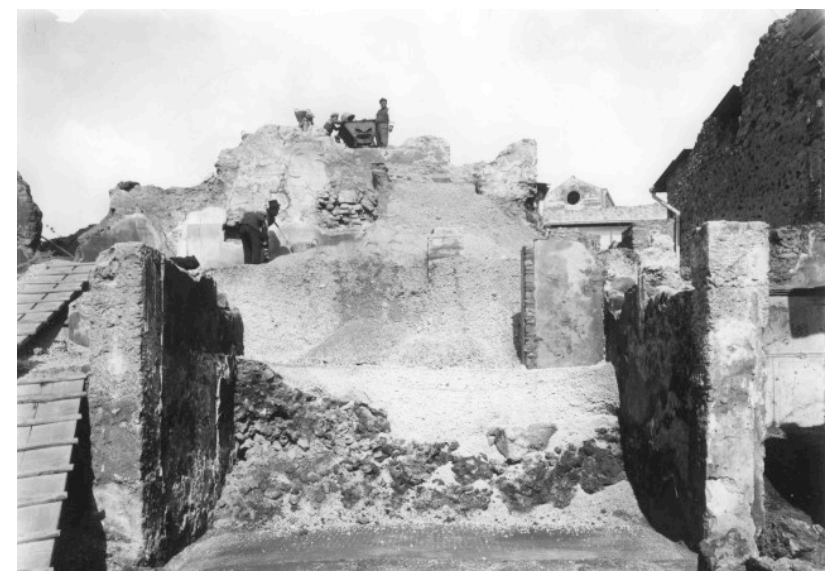

Figure 2. Historical photography of the excavation of 1926

\section{THE SURVEYS}

Since June 2014, the team of University of Naples "L'Orientale", under the supervision of Prof. F. Pesando, started the cleaning of the domus with the aim to carry out a detailed survey of the house and reconstruct the original structure of the Domus. During this intervention, several surveys were carried out in order to provide a complete 3D model of the house. Different methodologies and technologies were used and the final results compared in order to measure their accuracy, efficacy and velocity. At first, the domus was surveyed by an electronical total station, which is commonly used for archaeological investigation. Then, further two different interventions, both with un-calibrated photogrammetry, were planned to render the 3D model of the house.

The case study is particularly interesting because just after this survey the site was closed due to technical reasons. Therefore, the study of the site can continue based on the data recorded also through the $3 \mathrm{D}$ models.

\subsection{Survey with total station}

The total station is commonly used tool for "indirect" survey in archaeology; this methodology has become cheap and the software of the instruments particularly user-friendly also for no skilled operators. For the Stallius Eros survey, we planned the acquisition of points necessary to build a general plan of the house with the addition of few selected points for quoting the height and the uneven floors. Figure 3 shows the results of the survey after the processing in CAD software of the data obtained by means of the total station. This kind of operation has required a working day of two archaeologists with the need to make several movements of the total station and subsequent alignment and recalibration of the instrument. The result is the acquisition of enough points to outline the dimensions of the walls, potholes and drains water of the domus, and to lay down the averages heights and depths.

Even if it is possible to use the total station also to capture in detail the characteristics of the vertical stratigraphy of the walls of the house, this operation would require a long time and inevitable approximation of the smallest details.
Figure 3. Planimetry of Domus of Stallius Eros - Elaboration by total station and CAD 


\subsection{Terrestrial and aerial photogrammetry}

In order to solve some problems given by the total station, two different un-calibrated photogrammetical surveys were planned. The first work was carried out with a terrestrial "traditional" technique. About 1500 photos were acquired by Nikon D90 and some targets were measured by Total Station to define the geometry of the archaeological structure and to align the final model to the traditional survey. In terms of time-acquisition the work on the field required just few hours and two archaeologists. Figure 4 shows a snapshot of the model obtained by terrestrial photogrammetry with the location and the direction of each photo.

A second intervention was realized with a low cost drone (Apollo IdeaFly) equipped with a small digital camera (Canon PowerShot SX 260). In order to gain time to have a longer flight, and consequently a major number of shots, the drone was lightened and equipments reduced. Furthermore in order to reduce the vibrations of the quadric-copter, the camera was fastened directly to the drone in a perpendicular position under the drone by means a light attachment. For this reasons we didn't use a tool (Gimbal) for the fulfilment of the vertical axe of the camera in relationships to the vibrations of the quadriccopter. Also for this second aerial intervention some targets were acquired by the total station to assure the superimposition among the different surveys.

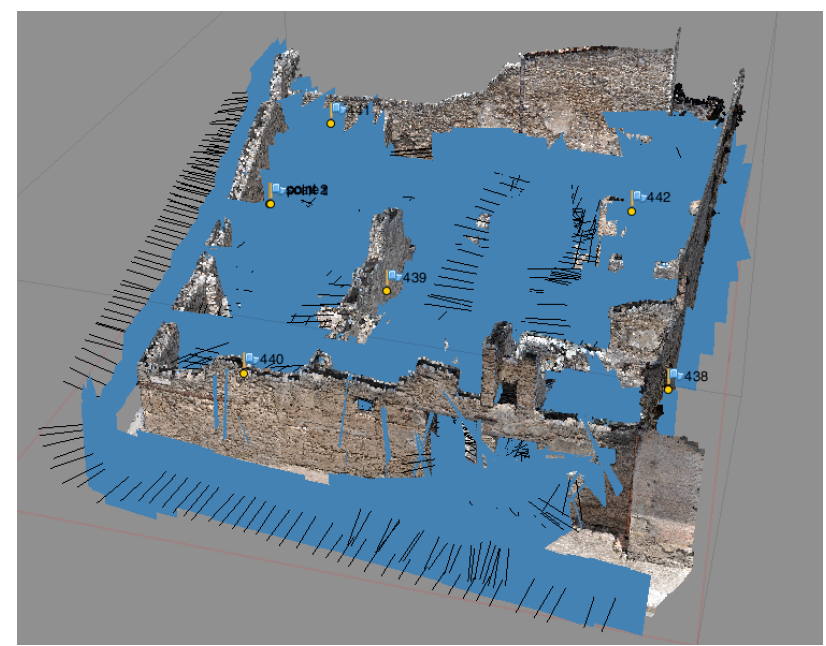

Figure 4. Terrestrial photogrammetry - location and direction of photos for 3D model

Some issues, typical for the surveys of archaeological buildings only standing partially, were dealt with the photogrammetical approach. The use of terrestrial and aerial shots was needed to integrate the two different perspectives from the bottom and top views. Stairs and poles were used for the acquisition of the higher part of the walls, while the roofs and the top part of the walls were acquired by the Drone. Furthermore, as the area is opened to tourists we were obliged to scheduled the flight before the opening of the archaeological area to the public, generally after $8.30 \mathrm{a} . \mathrm{m}$. when the light conditions are not optimal. To overcome the scarce light of the dawn, we modified sensibly the ISO, setting it to 400 , to gain visibility. The shutter speed is set to maximum, ie $1 / 2000$, due to the movement of the quadric-copter, and continuous shooting has guaranteed a number of shots greater than necessary. This redundancy of photos allowed the most high quality photos to be selected without losing overlap in pre-processing. The results obtained were very satisfying, bearing in mind that it was not possible to set a path before the flight either know the height reached by the quadricopter. During the 8 minutes flight, about two hundreds photos were taken from a height of about 15 meters.

\section{DATA PROCESSING}

Data processing has been carried out by the software for photogrammetry "Agisoft Photoscan" and some work on the mesh was made with software such as Geomagic Studio ${ }^{\circledR}$ and MeshLab. Despite of the various, not quite conventional, adjustments to the quadricopter, the result of the flight was quite satisfactory. The photographs, after a needed careful selection (at the end about 200 photos have been used), showed a very good superimposition and a good resolution which allowed to create a model of about 21.600 .000 faces. Figure 5 shows a view of a textured mesh.

The quality of the photos from the ground, was extremely higher than the quality of the photos taken by the drone.

All photos were processed in a single chunk, and have produced a dense cloud of about 98.000 .000 points.

For this reason, finally, a model of more than 225.000 .000 faces was created. However, such a complete model is not manageable by normal and also high performance computers. Therefore, during the mesh of the model some simplifications were applied, and the final model contains about one-tenth of the initial information. Figure 6 shows a top view of a textured mesh obtained by this technique. This final model was chosen after an accurate comparison of different versions with more or less accuracy, based on a sound balance between the manageability of the model and the level of accuracy necessary for the scopes of the survey.

In order to compare the models was chosen a wall very interesting for the analysis of the development of the house, because it shows one of the oldest construction techniques used in Pompeii, the "opera a telaio". This wall (namely the east wall of the atrium) is $6.25 \mathrm{~m}$ long, according to the reading obtained from the total station, while the same surface is $6.28 \mathrm{~m}$ in the model derived from terrestrial photogrammetry. Errors with the use of the total station are generally due to the instrument calibration and manual imprecision in the position of the targets necessary to record the position on the points to be acquired. This error is generally lower than $0.5 \%$ of the total length (less than $3 \mathrm{~cm}$ on $6.25 \mathrm{~m}$ ). For this reason the technique provides very reliable measures for linear walls and therefore is considered reliable for archaeological surveys at medium distance. Moreover the difference between the measures obtained by the total station and that obtained by the terrestrial un-calibrated photogrammetry is approximately $3 \mathrm{~cm}(6.25 \mathrm{vs}$ 6.28 respectively). Therefore the two techniques seems to have the same reliability. 


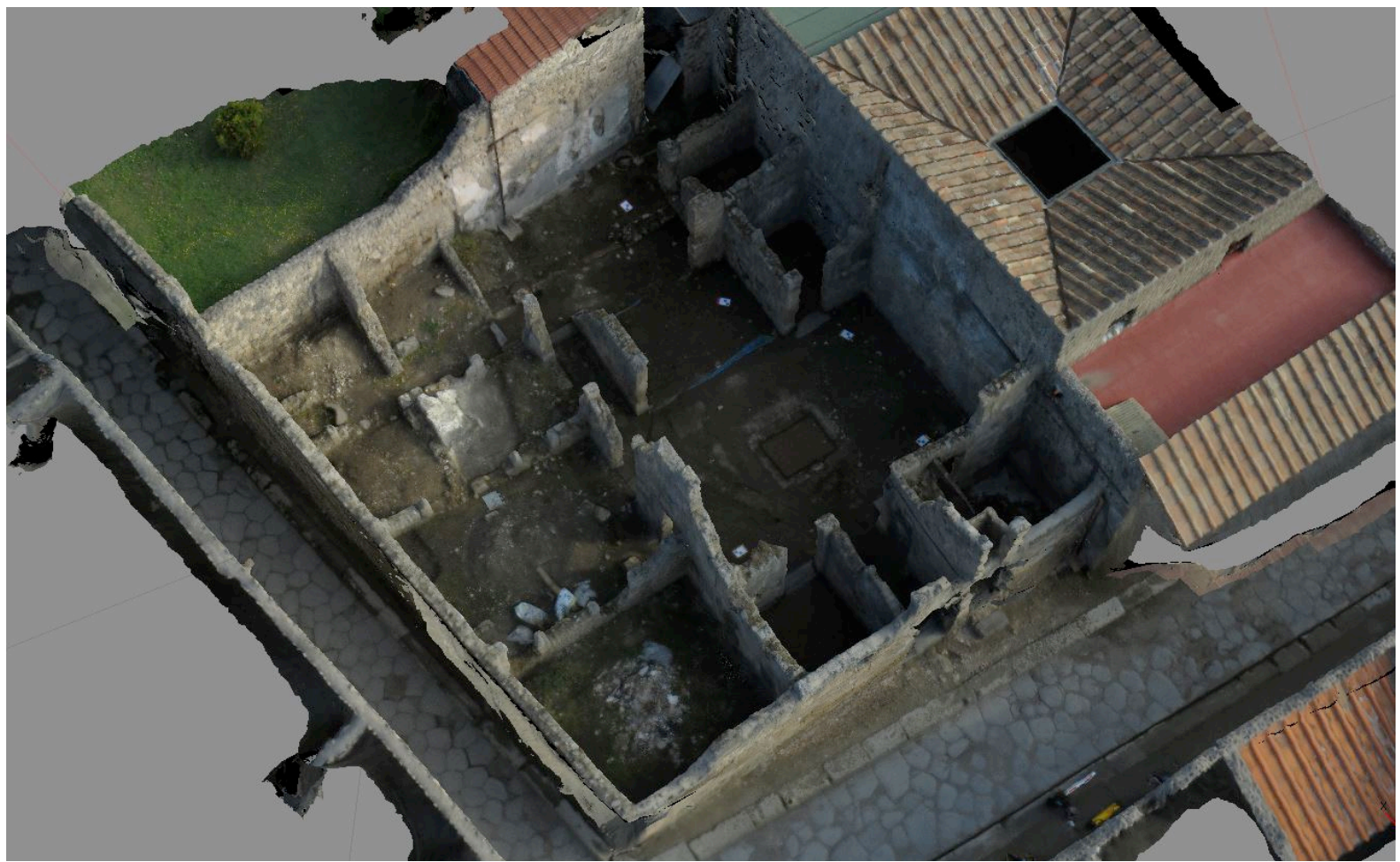

Figure 5. 3D model of Domus of Stallius Eros obtained by drone photogrammetry (top view)

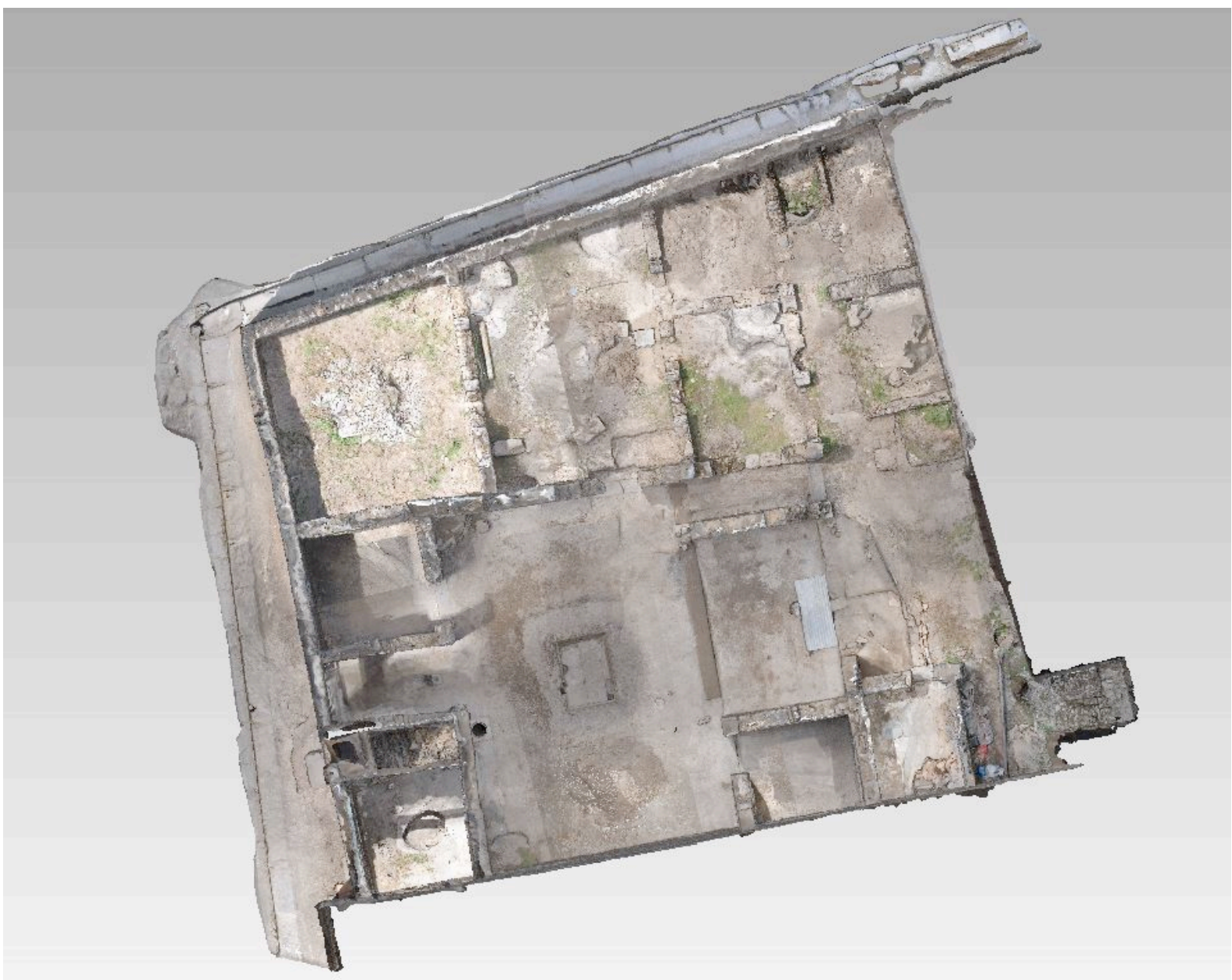

Figure 6. 3D model of Domus of Stallius Eros obtained by terrestrial photogrammetry (top view) 


\section{METHOD COMPARISON}

The primary objective of the surveys was to provide detailed and as accurate as possible support to archaeological research, with an intervention as possible low cost and bearing in mind the management issues that often involves a three-dimensional survey. The use and the integration of the results obtained by three allowed to highlight advantages and limitations of each techniques.

The use of the total station to obtain digital maps and phases plans is currently a routine on the archaeological excavation. Normally this task involves a simplification compared to the existing, because what archaeologists want to know are the dimensions of the built and its location in space. The details are commonly assigned to the cards, photos, sections, etc. By creating a three-dimensional model all this information may be extracted easily from the reconstruction. By setting maps and sections it is possible to obtain a detailed plan of the spaces allowing an easy analysis of the deterioration of a wall (figure 7).

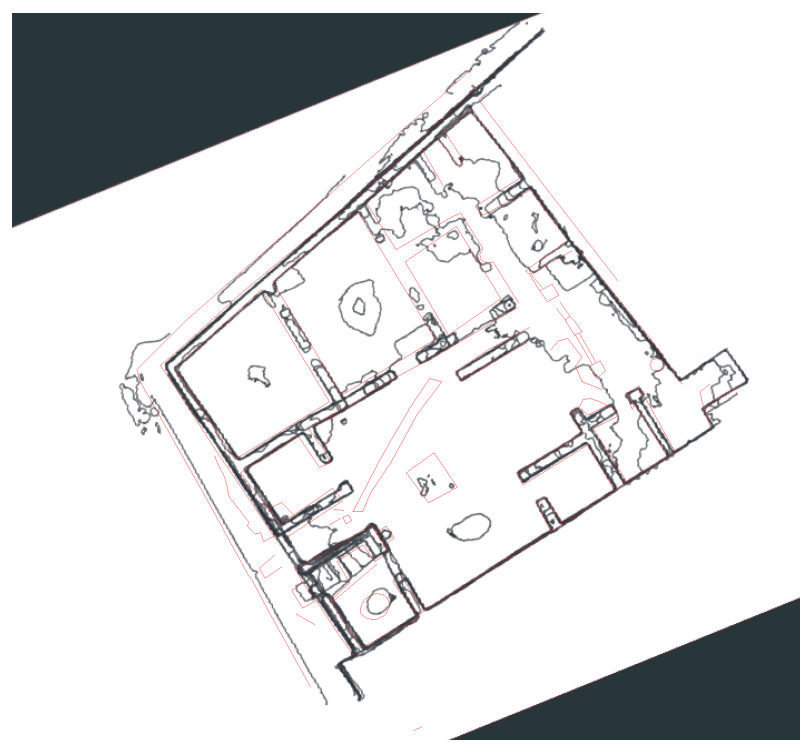

Figure 7. Overlap of the plants produced with total station (red) and with the 3D model (black)

As it is possible easily extracting by the 3D Model orthophotographs (Bornaz et al., 2006) and other rectified maps characterized by a detailed and coloured description of the surface, the archaeologist have available at any time a digital resource precise and measurable (scale 1:1) to identify stratigraphic masonry techniques and recognize the standing remains of the building.

This technique allows also to remove, during the processing phase of the reconstruction of the 3D model, any modern detail which impedes a complete reading and interpretation of the archaeological feature. Furthermore it is possible to extract features according to different phases or period in order to propose possible alternative or later reconstructions.

In the case of the examined domus it was impossible to have an overall view of the outer west wall, as it overlooks a narrow street (figure 8). A photomosaic straightened would certainly have created distortions resulting unreliable.

The model obtained by photogrammetry from the ground allows the extraction of this detailed information.

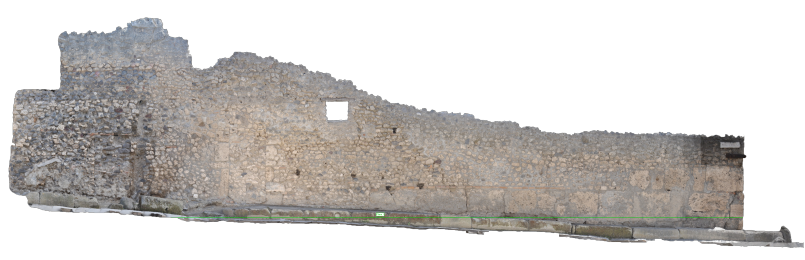

Figure 8. Ortho-photography of the west wall outside, extracted from the 3D model from terrestrial photogrammetry

The aerial photogrammetry low cost has not obtained a detail such as to allow the extraction of information of detail, but it has been found useful for a vision planimetric and to obtain an image of context (the roof, the top of the standing walls and the narrow streets surrounding the house).

\section{CONCLUSIONS}

The absence of stratigraphic information makes primary the correct reading of the vertical stratigraphy, as the only information source about the changes of the house (possible extension, reduction, different alignments). The classical approach of the archaeological study of masonry structures provides a catalogue with several photos. These photos have often a metric reference. In other cases these photo are rectified. Very rare are the ortophotos.

Orthophotos, plans and sections extracted from the 3D model become an essential tool for the study and understanding of the archaeological data. Furthermore the model allows the analysis of the state of the conservation of the monument and the study of the masonries can be used for a monitoring of the domus.

No standards are available to evaluate and measure the accuracy of $3 \mathrm{D}$ acquisition. To date, the final models obtained through different techniques with decimation and simplifications of the surfaces can be clearly compared only by extracting some specific and partial basic geometrical information (such as the height, length and depth). Further comparisons of the models could demonstrate that integrating different techniques is particularly useful for the surveying of parts of the standing structures. This integration not only solves visibility problems (a niche can not be seen from above, while a not accessible roof is not acquirable in terrestrial photogrammetry), but could improve the definition and measurement of the vertical and horizontal planes of the walls to reduce any distortion. The estimation of resolution in pixel or the number of polygons is not sufficient to demonstrate the reliability of a model, nor its chromatic properties. The increasing number of applications of terrestrial and aerial photogrammetry should provide data for a more detailed analysis of the limits of these techniques and a large scale use of these methodologies for rapid 3D acquisition.

\section{ACKNOWLEDGEMENTS}

The authors would gratefully acknowledge Professor Fabrizio Pesando, for encouraging this work and providing input to the research and Dr. Marco Giglio for providing survey data through the total station.

\section{REFERENCES}

3D Sistem - Geomagic Solution, 2012. Geomagic Studio 2012.1.1, User guide

Agisoft 2014. Agisoft PhotoScan User Manual Professional Edition, Version 1.0.3 
Allison P. M., 2004. "Pompeian Households: An On-line Companion is a publication of The Stoa: A Consortium for Electronic Publication in the Humanities", Ross Scaife, ed. http://www.stoa.org/projects/ph/house?id=5

Bitelli, G., Tini, M.A., Vittuari, L., 2003. "Low-height aerial photogrammetry for archaeological orthoimaging production". ISPRS Archives Vol. XXXIV, Part 5/W12, pp. 55-59.

Bornaz L., Dequal S., Lingua A., 2006. "L'ortofoto solida di precisione: un prodotto innovativo per la rappresentazione e la gestione dei dati tridimensionali". Atti Conferenza nazionale SIFET, Taranto.

Chiabrando F., Lingua A., Maschio P., Rinaudo F., Spanò A. (2012). Mezzi aerei non convenzionali a volo autonomo per il rilievo fotogrammetrico in ambito archeologico. In: Una giornata informale per i 70 anni del Prof. Carlo Monti - 3 Maggio 2012, Milano, 3 maggio 2012. pp. 1-12

Eisenbeiss, H., Lambers, K., Sauerbier, M., Zhang, L., 2005. "Photogrammetric documentation of an archaeological site (Palpa, Peru) using an autonomous model helicopter". ISPRS Archives Vol. XXXIV-5/C34, CIPA, Torino, Italy ,pp. 238-243.

Maiuri, A. 1929. Pompei - Relazione sui lavori di scavo dall'aprile 1926 al dicembre 1927. In Notizie degli Scavi di Antichità, Serie 6, n.. 5, pp. 354-476. 